\title{
Imagens da memória: a pandemia nas projeções urbanas
}

\section{Images of memory: pandemic in urban projections}

Carlos Falci ${ }^{1}$ 


\section{Resumo}

De que maneira as projeções urbanas podem ser pensadas como memórias sobre a pandemia da covid-19? O presente artigo gira em torno dessa questão, buscando investigar a noção de memória a partir de seus modos de existência enquanto registro de narrativas. Nesse sentido, o texto descreve as ações da rede de projecionistas/ coletivo Projetemos e traz uma análise do seu perfil no Instagram. Apresentamos uma breve investigação sobre a temática da vacinação no Brasil e como ela aparece nas projeções postadas no perfil do grupo. O que caracteriza esse arquivo da pandemia? De que maneira as memórias de diversos acontecimentos relacionados à pandemia existem no perfil @projetemos do Instagram?

\section{Palavras-chave}

Memória, pandemia Covid-19, Projetemos, arquivos.

\section{Abstract}

How can urban projections be thought of as memories about the Covid-19 pandemic? To understand how the group of activists Projetemos creates urban projections and offers us a special way to see Covid-19 in Brazil, this article investigates the forms of memory. More specifically, we explore the problem surrounding immunization and how this content features in projections exhibited on Instagram. What characterizes the pandemic archive of Projetemos on Instagram? How does memories related to the Covid-19 pandemic exist on their Instagram profile?

\section{Keywords}

Memory, Covid-19 pandemic, Projetemos, archives. 
Projeções urbanas são atos por sua própria natureza efêmeros, feitos para durar num tempo delimitado e para serem vistos por quem está nas ruas quando elas são exibidas. Não são necessariamente pensadas para virarem arquivos, ou como forma de registro de algum acontecimento. As projeções são o próprio acontecimento. Mesmo que estejam relacionadas a fatos que são o objeto da projeção, há um caráter de impermanência que caracteriza a própria ideia de projetar imagens num ambiente urbano. Diante dessas constatações, como pensar a relação entre projeções urbanas e memória? Mais ainda, como pensar as projeções urbanas como memórias da pandemia da covid-19, que demanda que fiquemos em casa como medida de proteção e cuidado coletivo, e faz com que não estejamos nas ruas para ver as imagens nas empenas de prédios, em fachadas de casas ou em muros?

Este artigo trata das questões acima colocadas e faz parte de uma pesquisa de escopo mais amplo, qual seja, investigar a memória a partir de seus modos de existência. Neste texto, faço uma descrição da rede de projecionistas/coletivo ativista Projetemos e uma análise de seu perfil no Instagram - @projetemos. Mais especificamente, analiso duas temáticas sobre a pandemia presentes nas projeções, com o objetivo de verificar como as memórias da pandemia aparecem no perfil, a partir dos registros ali apresentados. Como elas passam a existir na página do Instagram, cujo objetivo é dar visibilidade a projeções urbanas feitas por mais de 150 pessoas espalhadas pelas cidades do Brasil?

\section{Dos modos de existência da memória}

Apresento como proposição um caminho metodológico que entende memória a partir do modo como ela se comporta quando surge sob determinadas formas, que não serão pensadas somente como materialidades constituídas. Não associo materialidades a suportes definidos, mas a comportamentos. Um material se comporta de maneiras específicas, exibe certas qualidades dependendo do estado em que se encontra, e oculta outras quando o vemos por um ângulo distinto. 
Discutir ou tentar conceituar memória significa compreender que o conceito é objeto de análise em diversas e variadas disciplinas e campos do conhecimento, recebendo múltiplas adjetivações e acepções, tais como: memória coletiva, memória social, memória individual, memória de longo prazo, memória episódica, memória semântica, entre um conjunto muito extenso de maneiras de falar da memória. Adoto aqui a opção de olhar para as plataformas e técnicas de registro como formas de externalização da memória (STIEGLER, 1998, 2009), sem buscar caracterizar de que tipo de memórias estou falando.

Ao falarmos da pandemia da covid-19, é possível lembrar de acontecimentos que podem se encaixar em cada uma das formas conceituais acima. Como uma não é necessariamente exclusiva em relação às outras, assumo o intercruzamento conceitual como uma característica fundamental. Entendo o que poderia ser visto como uma instabilidade conceitual sobre a memória como uma potência desse conceito. Indo ainda mais longe, assumo a memória como um acontecimento (CANDAU, 2016), como um processo, cuja materialização será forçosamente incompleta, sujeita a revisões e produtora de tensões em relação ao que se pretende registrar (um evento, um grupo social, uma pessoa, um fato, um acontecimento histórico etc.). Ecoando "o mal de arquivo" (DERRIDA, 2001), a materialidade do arquivo e o tipo de arquivo que se escolhe para guardar uma memória condicionam toda a forma de produção dessa memória; aquilo mesmo que será ou não arquivado o será em função do material escolhido para realizar tal ação.

Olho para a materialidade e modos de existência da memória porque entendo que políticas de memória se relacionam com a transmissão dela. Logo, estamos tratando de registros, de sua durabilidade, da capacidade e possibilidade de fazê-los, da autorização e autoridade para registrar e transmitir esses arquivos, bem como da autonomia para ter acesso aos meios e utilizá-los. Embora não esteja discutindo políticas de memória neste texto, olhar para seus modos de existência me parece uma ação que inevitavelmente toca em questões políticas, pois se trata de dizer como as memórias são registradas e quem ou o que é responsável por tais escolhas. 
No âmbito dos registros, há formas muito variadas de materializar lembranças de uma pessoa ou de grupos sociais, que podem começar com o testemunho (RICOEUR, 2007), o falar dessas memórias. Para além da voz daquele que testemunha, podemos enumerar ainda, como elementos de materialização de lembranças: arquivos, rastros, traços, documentos, discursos escritos ou falados, metadados, pinturas, desenhos, a própria língua, museus, bibliotecas, arquivos públicos, plataformas empresariais na web, perfis em plataformas de distribuição de conteúdo audiovisual, entre um conjunto que pode soar inesgotável.

Arquivos são modos de externalização da memória humana e podem aparecer em vários formatos, com qualidades distintas entre si. Isso significa dizer que cada tipo de arquivo armazena não só o conteúdo a ele destinado, mas congrega também particularidades técnicas que ajudam a condicionar o tipo de narrativas de memória que o arquivo irá carregar. Chamo a atenção para um primeiro comentário encontrado em $O$ mal de arquivo, e que nos serve de baliza inicial para esta discussão, qual seja, o fato de que não há arquivo sem um lugar de impressão, sem uma materialidade de inscrição. Assim, quando trato da memória como arquivo, será justamente pensando nas várias formas de inscrição da memória. Por isso, entendo que o perfil do coletivo Projetemos no Instagram é uma maneira de inscrever, de imprimir as projeções, de dar a elas um lugar, uma primeira condição para externalizar a memória das ações dos projecionistas.

Arquivos residem em uma morada, em um lugar ordenado, capaz de guardar a origem dos fatos e mantê-los também ordenados. As inscrições são essa morada, onde a memória arquivada pode se de-morar, pode restar por um tempo. É como se a memória encontrasse um corolário físico para o que ela própria é enquanto existência: uma demora no tempo. Mas como falar da demora de uma projeção em um espaço público? O arquivo reforça a percepção da memória como algo que fica, que se prolonga. Ainda que possamos falar do arquivo como um local capaz de nos remeter à origem dos fatos, das lembranças, como ele é uma inscrição, resultado de uma ação de imprimir em uma materialidade aquilo que se passou enquanto ato, o arquivo é também um ordenamento, 
produz comportamentos em relação ao material que recebe. É o que Derrida (2001) enfatiza ao dizer que o arquivo delimita o que será arquivado; assim, os arquivos são também arquivantes.

Colocar a memória sob a guarda de arquivos e dos arcontes, aqueles que são responsáveis pela morada dos arquivos (sejam humanos ou não-humanos), significa também realizar escolhas, recortes; produzir a memória aí guardada e o tempo a que essa memória faz referência:

[...] a estrutura técnica do arquivo arquivante determina também a estrutura do conteúdo arquivável em seu próprio surgimento e em sua relação com o futuro. $O$ arquivamento tanto produz quanto registra 0 evento. É também nossa experiência política dos meios chamados de informação. (DERRIDA, 2001, p. 29)

Chamo a atenção para o surgimento daquilo que será arquivado, a noção de produzir e registrar o evento ao mesmo tempo. No caso das formas de registro que carregam a possibilidade de colocar em circulação ao mesmo tempo que registram (aparatos conectados em rede via aplicativos de distribuição de conteúdo), há como que uma equitemporalidade em que passado, presente e futuro passam a ser uma medida não mais física somente, mas fundamentalmente ligada aos modos de ordenamento das plataformas em que um determinado conteúdo irá circular. As técnicas de externalização não podem definir o momento a ser arquivado, mas sim a maneira como ele passará a fazer parte das instituições responsáveis por armazenar e fazer circular a memória ali inscrita.

Derrida chama os dispositivos técnicos de arquivamento de próteses da memória viva, o que me lembra os vários tipos de agenciamento entre humanos e não-humanos, que tornam cada vez mais borrada a fronteira entre o que são as "leis" do arquivo e o próprio arquivo em si; o conteúdo que o produz e o que ele armazena. A estrutura da interface do Instagram, bem como a proposição dos idealizadores do Projetemos de utilizar o perfil para mostrar as projeções feitas em cidades ao redor do país, exemplifica como as particularidades técnicas da interface modulam a memória do coletivo. Ao permitir o agrupamento de 
projeções realizadas em locais completamente distintos, mas que seguem a lógica de uso de empenas de prédios, de fachadas de casas, muros, sempre usando a cidade, o Instagram aproxima as visualidades espacialmente distantes e dá um caráter de conjunto muito potente ao trabalho do Projetemos. É como se a rede de projecionistas ficasse evidente através da plataforma.

Defender o arquivo como um comportamento me faz seguir a dupla existência do arquivo: como elemento, mas também como capaz de ação, já que ordena e delimita o que será arquivável ou não. Preserva-se assim a ambivalência do arquivo, como ordem e como origem, que está na raiz da palavra, quando nos remetemos à raiz arkhé. As escolhas relativas ao que será arquivado dizem respeito à noção de consignação, autorização ou institucionalização dos documentos arquivados. Como consequência, as memórias inscritas nos arquivos terminam também por sofrerem da mesma lógica, ou se sujeitarem à ideia de uma reunião orgânica de fatos cuja heterogeneidade deve ser ou expurgada, ou mantida sob estrito controle.

Podemos falar do arquivo como um conjunto de documentos reconhecidos por alguma instituição, como afirma Paul Ricoeur (1994). Isso não elimina a ambivalência que almejo enfatizar, uma vez que o ato de reconhecimento não é parado no tempo; e reconhecer significa dizer que aquilo que é objeto dessa ação tem um lugar de existência dentro de uma ordem de elementos possível. Reconhecer é também produzir um lugar de memória, ou seja, colocar em algum lugar alguma coisa. O arquivo tem caráter de coisa, de objeto. Se o arquivo é a exteriorização da memória, ele é também a marca da falta dessa memória; ele é um outro dessa memória. Daí sua potência de equivocação, daí o mal de arquivo, que "destrói" não o arquivo em si, mas aquilo que ele deveria guardar.

A própria ideia de instituir o que pode ou não ser inscrito como memória digna de se de-morar numa forma qualquer de inscrição já traz em si, paradoxalmente, a possibilidade de alteração dessa memória. O que é feito para durar pouco tempo, como as projeções, e de onde vem também a força da ação, se torna uma ação de resiliência em função da plataforma de arquivamento. Ricoeur (2007) diria que o 
arquivo fala quando aquele que testemunha não está presente, independentemente da causa dessa ausência.

Obviamente, as ausências não são inertes, e se revestem de forte conteúdo político, em várias ocasiões. Todo arquivo produz a ordem, seja conservando relações, seja criando relações. Dois polos a partir de uma mesma lógica, aquela do arquivo enquanto uma prática, enquanto elemento a ser praticado. Por que já coloco aqui a questão da prática? Porque entendo que os arquivos são formulações, ou melhor, para ecoar Foucault (1999), se assemelham a formações, que irão ecoar ordens mais duras ou mais flexíveis, mais conservadoras da ordem ou mais criadoras da ordem.

Há dois grandes movimentos gerais correspondentes ao ato de arquivar memórias: por um lado, há conteúdos que precisam ser ou que se deseja que sejam arquivados, não importa qual seja o tipo de dispositivo ou aparato a ser utilizado para o registro; por outro, convivemos com uma miríade de formas de registrar, de externalizar a memória e, muitas vezes, é a presença e o modo de registrar desses aparatos que irão se impor sobre determinados fatos, criando assim uma memória de acontecimentos que até então não se supunham como algo a ser lembrado (pela necessidade, pelo desejo, pela importância).

Cada tipo de arquivo tem características físicas e qualidades de registro específicas, e esses elementos interferem diretamente no modo como as narrativas de memória serão neles construídas. Basta imaginarmos as diferenças óbvias entre o registro sonoro e o imagético para compreender tais diferenças, mas mesmo quando tratamos do registro de imagens em movimento, por exemplo, há distinções entre o registro com a câmera do aparelho celular e o registro com uma câmera fotográfica que também faz vídeos, e com uma câmera que grava imagens em formato digital profissional para cinema.

Esses aparatos se organizam de maneiras diferentes no que diz respeito ao tipo de elemento físico a ser capturado. Os arquivos daí resultantes também terão pequenas distinções relativas ao que trazem de cada acontecimento, e essas diferenças indicam que as memórias aí arquivadas também podem conter pequenas diferenças. É o que acontece quando olhamos para os vários 
perfis ou páginas do coletivo Projetemos nas plataformas de conteúdo na web (Instagram, Facebook, Twitter). Em cada uma delas, as ações de projeção dão lugar a acontecimentos cuja aparência é distinta, ainda que o fato que gera os acontecimentos seja o mesmo. A plataforma escolhida performa uma memória arquivada e se torna parte do testemunho da projeção, daquilo que ela articula e conta sobre um conteúdo particular ali exibido.

\section{A rede Projetemos e o perfil @projetemos no Instagram}

Segundo Mozart Santos (CORONAVIDA..., [2020]), um dos idealizadores da ação, o Projetemos tem relação com o fato de ele morar na região metropolitana de Recife e por conta da pandemia, ao ter que ficar em casa, longe do centro da cidade, perceber que a quarentena não estava acontecendo. Com a recomendação do isolamento social, as pessoas deixaram de ocupar as regiões centrais da cidade para se manter em suas casas. Entretanto, o que Mozart percebeu é que, ao final da tarde, as pessoas ocupavam as ruas, desciam para as áreas de lazer coletivas, jogavam bola e não faziam a quarentena. Surgiu a ideia de criar uma rede que trouxesse dados sobre a pandemia, buscando mostrar a importância do isolamento social e como conviver e se proteger, o que envolvia também lutar contra a desinformação e contra alguns protagonistas do movimento negacionista da pandemia. Junto com Felipe Spencer, VJ de Recife, e Bruna Rosa, cientista política, começam a estruturar a rede, que já agrega mais de 150 pessoas em todo o país, entre VJ, projecionistas amadores, designers, cartunistas, jornalistas, entusiastas do projeto, entre outros participantes. Para Felipe Spencer, "a ideia era gritar nas paredes o que a gente não consegue gritar na orelha das pessoas" (SANTOS, 2020).

Mozart divide a construção do movimento em três etapas. Num primeiro momento, fizeram o convite para colegas VJ profissionais, através de redes de contato já existentes, apresentando a proposta e trocando informações. Era um grupo que já tinha experiência em mapear empenas de prédios e fazer vjing, contando com projetores potentes e outros equipamentos necessários. Eles formaram o que Mozart chamou de equipe técnica profissional e, em poucas 
semanas, apareceram outras pessoas para alimentar o processo. Assim, na segunda etapa entraram profissionais de outras áreas: designers, jornalistas, pessoas que tinham afinidade com o movimento e com a proposta, que se tornaram os produtores de conteúdo.

Por fim, numa terceira etapa, surgiram os voluntários, que não eram VJ profissionais ou designers. Esse grupo é formado por pessoas que tinham projetor em casa, ou mesmo aquelas que não tinham, mas queriam projetar, participar do projeto. Começaram a pedir informações sobre projetor para comprar, como fazer mapeamento e projetar nas paredes, empenas de prédios etc. Mozart entende que esse foi o movimento mais importante de todos, pois permitiu "dar voz a uma galera que se sente representada pelo que estamos falando, pelo que estamos fazendo" (SANTOS, 2020). Atualmente, o Projetemos tem ramificações em Nova York, Ásia, Europa e Argentina. No Dia Mundial da Saúde, segundo Mozart Santos, fizeram um projetaço mundial.

Com a demanda provocada pela terceira etapa, o grupo converteu o site do Projetemos em uma ferramenta para que as pessoas aprendessem a projetar e fizessem suas projeções em qualquer lugar do país. Os VJ e vários outros participantes da rede produzem conteúdo para um drive coletivo, e esse repositório é aberto para que as pessoas façam suas projeções. São criadas pautas diárias, com material produzido sobre um conteúdo específico, mas o grupo reitera que não há uma determinação sobre o que projetar. A ideia é que cada um faça as projeções que deseja. O objetivo geral é que seja um trabalho coordenado a favor da informação e da conscientização contra a pandemia e contra o governo federal, no que tange à gestão da crise sanitária.

Em várias entrevistas com os idealizadores, fica claro o papel político que enxergam na plataforma e nas ações de projeção, principalmente relacionadas à pandemia, mas não só a esse tema. Além disso, é importante destacar o caráter estético do projeto, considerando novas formas de ocupar espaços públicos, as ruas e cidades vazias durante a pandemia. Dar voz a grupos diversos através das 
projeções, imagens mapeadas e ações coletivas audiovisuais parece ser um dos pilares do projeto, cuja amplitude abrange hoje várias capitais de todo o país.

A potência do trabalho está associada ao trabalho de $\mathrm{VJ}$ e ao vjing, um tipo de atividade que diz respeito "à manipulação de imagens fixas ou em movimento, figurativas ou abstratas, que são apresentadas em galerias de arte, em raves, em festas ou em boates, a partir de improvisações com um banco de imagens previamente selecionado" (MORAN, 2005, p. 157).

$\mathrm{Na}$ análise do perfil do Instagram, podemos encontrar 2.412 publicações $^{2}$ que compreendem, em sua totalidade ou quase totalidade, projeções feitas em várias cidades do país. Vejo a página como um grande arquivo de projeções e material audiovisual, uma memória contemporânea que começa como memória da pandemia, mas ganha uma magnitude muito mais ampla, porque traz temas sobre a classe política brasileira; temas relacionados às ditas "minorias" sociais (LGBT; pessoas negras; povos originários); temas ambientais, entre outros. Essa ampliação de temas revela uma faceta importante do trabalho de memória, que é o fato de um arquivo, de uma memória arquivada, estar sempre relacionado a um contexto de arquivamento, muito mais amplo do que o registro em si. Projeções em escala urbana se mostram ainda mais potentes nesse sentido porque trazem essa rede para o espaço da cidade, mesmo que não seja feito de maneira explícita.

Ver a página e consultar os posts, ainda sem entrar em cada um deles, já permite perceber a enorme e importante diversidade de temáticas abordadas pelo coletivo de projecionistas. Listo aqui alguns desses temas, numa classificação que poderia ser expandida e modificada de acordo com os critérios utilizados evidência de que os modos de existência da memória são intimamente relacionados às formas de categorizar os registros. A lista também acaba por destacar quais são os indicadores dos temas de memória nesses registros.

Vejamos uma proposta de classificação: 8M (Dia internacional da Mulher); Marielle Franco Presente; Padre Júlio Lancelloti; gastos do Exército; 2 anos do 
crime ambiental da Vale em Brumadinho; defesa do SUS; início da vacinação; falta de oxigênio em Manaus; vacina Butantan; Vidas Negras Importam; luta contra o racismo; assassinato no supermercado Carrefour; luta pelos direitos dos povos originários; apagão no Amapá; crime da Vale na bacia do Rio Doce 5 anos sem reparação; estupro de Mariana Ferrer; fome no Brasil; luta contra as queimadas e contra o ministro do Meio Ambiente; desmatamento da Amazônia; SOS Pantanal; mensagens sobre o próprio @projetemos; orientações sobre como projetar; visibilidade LGBTQ+; luta pelos direitos das mulheres; luta contra violência de gênero; projeções com número total de mortes em datas específicas - 100 mil mortes, 200 mil mortes etc.; greve dos trabalhadores de entregas via aplicativos (Breque dos Apps); defesa do IPHAN; luta dos quilombolas; assassinato de João Pedro; Dia Internacional da Enfermagem; mensagens pessoais de conforto relativas ao distanciamento social ou para pessoas hospitalizadas com covid; defesa da democracia; fora Bolsonaro; \#ficaemcasa; \#DefendamoSUS; defesa da quarentena.

Tais grupos podem ser expandidos caso se faça uma opção, por exemplo, por analisar visualmente cada projeção, para além do acontecimento ao qual ela faz referência. A lista acima mistura várias formas de classificação, propositalmente, como forma de mostrar possíveis maneiras de organização de um conjunto de imagens que não foi feito, originalmente, para se transformar num arquivo. Tanto é assim que, a partir do grupo de WhatsApp que articula vários projecionistas ao redor do país, é possível acessar um drive com conteúdo para ser projetado. A classificação que encontramos lá é bastante diferente da aqui criada, apenas navegando pelo perfil no Instagram. Não há nenhuma novidade nessa constatação, mas a diferença deixa bem claro o papel que o arquivamento tem ao nominar as imagens e relacioná-las a determinados eventos. Esse é o ato que produz a memória de cada um dos acontecimentos projetados, que autoriza as associações entre imagens e fatos; é como se os rastros das projeções só se tornassem rastros após a entrada no arquivo, ou seja, no perfil do Instagram.

Para pensar a memória da pandemia e seus modos de existência a partir do trabalho do Projetemos, tomamos a questão da vacinação como um pequeno 
exemplo para verificar como o tema aparece no perfil do Projetemos na plataforma Instagram. O objetivo é investigar os modos de existência dessas memórias dentro da plataforma e do perfil.

Em relação à questão da vacinação, há projeções feitas em cidades muito distintas, com várias formas de abordar o tema, criando uma memória multifacetada, que faz referência a acontecimentos diários noticiados nos grandes portais, mas também a questões de fundo, como o uso do personagem Zé Gotinha e a necessidade de se criar uma campanha coordenada de vacinação no país. As projeções nos permitem compreender que a questão da vacinação abrange desde a proteção de pessoas idosas, com comorbidades, até a volta das aulas presenciais e a defesa e importância do SUS no processo de vacinação em massa da população brasileira. O espectro de conteúdo das postagens revela ainda uma amplitude maior da discussão, porque nos leva a conhecer a importância de instituições públicas de pesquisa, como o Instituto Butantan e a Fundação Oswaldo Cruz. Em relação ao arco temporal, as postagens nos levam de volta a 29 de julho de 2020, quando se discutia a questão da volta às aulas com vacinas.

As projeções já reivindicavam "sem vacina sem aula" em várias capitais do país. Em abril de 2021, a pauta continua lembrada diante da ausência da vacinação em massa tanto para estudantes, quanto para trabalhadores da educação, enquanto Congresso e Senado tentam votar um projeto de lei que estipula a educação como serviço essencial que, logo, que não pode parar mesmo em meio ao momento mais letal da pandemia. Se estivéssemos falando de ações urbanas somente, poderíamos considerar esse arco temporal bastante extenso, considerando a efemeridade das projeções. No entanto, na página do Instagram, o tema não deixa de se fazer presente, mesmo que misturado a outros conteúdos que aparecem ao rolarmos a página do perfil. Se há uma "distância" entre as projeções nesse movimento, ela é infinitamente menor do que os seis meses que separam a projeção citada acima de que pede que o Zé Gotinha venha nos salvar, datada de dezembro de 2020.

Seguindo o que podemos chamar de uma lógica das ações efêmeras em espaços urbanos, temos faixas de conteúdos nas páginas do Instagram. 
Junto à projeção de dezembro, logo encontramos outras mensagens sobre a vacinação, o que de certa maneira permite perceber que, num determinado período, a questão da vacina foi tema de várias projeções ao longo do país. Cabe fazer um estudo mais amplo para comparar cada uma dessas aparições com os fatos e matérias jornalísticas que circulavam em cada época, de maneira a compreender as redes de memória que se formam nas plataformas e fora delas, como nos grupos de WhatsApp. No entanto, é possível constatar que se as projeções são, por sua natureza, efêmeras, a plataforma Instagram confere a essas memórias uma perenidade inusitada. A partir de um olhar panorâmico sobre a página do Projetemos, teço algumas considerações sobre os modos de existência da memória sobre a pandemia da covid-19 em projeções urbanas publicadas no Instagram.

\section{Uma memória da pandemia em projeções urbanas?}

O primeiro ponto que chama a atenção nos registros encontrados no perfil da rede Projetemos no Instagram é o fato de a própria visualidade da plataforma remeter a agrupamentos de janelas de um apartamento, por exemplo. Segundo Mozart Santos, um dos idealizadores do projeto, a rede surgiu da necessidade de dar visibilidade às experiências que diversos grupos sociais estavam vivenciando em relação à pandemia, em função da quarentena e de suas particularidades ao redor do país. A projeção em fachadas de prédios, muros e nas ruas foi também uma forma de ocupar simbolicamente os espaços vazios das ruas, em função das medidas de distanciamento social. O Instagram, nesse aspecto, funcionou como uma maneira de fazer as imagens se manterem "no ar", circulando para além das projeções nas empenas, fachadas, muros etc. (FERRAZ, 2020). Ou seja, ao fotografar a projeção feita numa noite, ela ganharia uma materialidade para além do evento diário, passando a ter permanência, perenidade. Uma memória arquivada. Mas o que caracteriza esse arquivo da pandemia? De que maneira as memórias de diversos acontecimentos existem no perfil @projetemos do Instagram?

Antes de abordar as perguntas acima, é preciso ter em mente que as ações do Projetemos são parte de um conjunto maior com vários antecedentes históricos, 
relacionados a: ocupações urbanas; expanded cinema; cena VJ (projeções em festas, shows com manipulação de imagens ao vivo em grandes festivais), flash mobs, entre outros. No caso do trabalho dos VJ, como destaca Patrícia Moran (2005), há uma manipulação de imagens a partir de bancos. E aqui penso na importância do trabalho de memória e das políticas de memória. Como lembrar da pandemia? Onde as memórias da pandemia podem habitar? E como elas são armazenadas, em que locais, acessíveis a quem? O fato de o Projetemos ter perfis no Instagram, Facebook e em outras plataformas mostra a importância desses meios como repositórios de memória contemporâneos. E cada uma dessas plataformas acaba por criar formatos de arquivamento específicos, formas registro respectivamente adequadas.

No caso do Projetemos, é importante notar que desde o início houve uma percepção de manter as projeções "ativas" através do registro das projeções e divulgação via Instagram e outras plataformas. Assim, o trabalho de memória aqui não trata apenas de um registro de ações passadas, mas de uma memória para o futuro, para um tempo futuro, como de fato é o trabalho de memória. Arquivar documentos, fatos, acontecimentos não é guardar o passado, mas revisitar o passado no presente, de forma a criar um futuro. Essa frase pode ser lida em vários autores com pequenas modificações, e sua repetição só mostra a força da memória como uma ação de construir o tempo. Nesse sentido, o coletivo Projetemos cria uma memória possível da pandemia, como talvez seja o caso de todo arquivo.

Uma das diferenças fundamentais, nesse caso, é a abertura do projeto para criações por parte de qualquer um que queira projetar ou criar conteúdo para as projeções, além de um site em que o modo de projetar é explicado, compartilhado e aberto para quem quiser criar seus próprios arquivos. Nesse sentido, a lógica de ordem e comando presentes na raiz da palavra arquivo está aberta a uma coletividade cujas regras são definidas e discutidas coletivamente. Os arcontes, nesse caso, não estão definidos a priori, embora exista um direcionamento político sobre o tipo de mensagem a ser projetada.

Considero o perfil @projetemos, no Instagram, como um arquivo dinâmico, porque ele carrega não só uma organicidade entre as várias imagens, mas porque 
dá a noção de conjunto para uma ação que se faz espalhada em todo o Brasil e que talvez não aparecesse dessa mesma maneira caso não estivéssemos na pandemia e a plataforma utilizada fosse outra. O Instagram, nesse caso, acaba por se assemelhar muito a um conjunto de projeções em janelas, sem perder o seu caráter de arquivo. E como as projeções podem continuar a ser compartilhadas, há uma primeira noção de dinamismo associada a esse movimento. A ideia de arquivo dinâmico se relaciona ao fato de que cada postagem continua a ser "projetada" quando acessamos a página, e o tempo dessa projeção se dissocia da temporalidade da projeção física realizada em alguma data e em algum lugar do país. Essas indicações permanecem lá, mas junto a elas há uma temporalidade que é a da própria interface. Assim, a memória da pandemia continua a se refazer constantemente em projeções urbanas, tanto de maneira efêmera quanto de forma perene, em função de um modo de existir próprio de plataformas de distribuição de conteúdo audiovisual na web.

\section{Referências}

CANDAU, J. Memória e identidade. São Paulo: Contexto, 2016.

CORONAVIDA e expressões político-artísticas na cidade. [S. I.: s. n.], [2020]. 1 vídeo (73 min). Publicado pelo canal do IAB SP. Disponível em: https://youtu.be/ u4EbCkQUzdA. Acesso em: 25 abr. 2021.

DERRIDA, J. Mal de arquivo: uma impressão freudiana. Rio de Janeiro: Relume Dumará, 2001.

FERRAZ, M. G. Projeções luminosas se espalham pelo país como armas de luta e conscientização. Artebrasileiros, São Paulo, 20 abr. 2020. Disponível em: https://bit.ly/ 3i4bBO6. Acesso em: 25 abr. 2021. 
FOUCAULT, M. A ordem do discurso. São Paulo: Loyola, 1999.

MORAN, P. VJ em cena: espaços como partitura audiovisual. Revista Contracampo, Rio de Janeiro, n. 13, 2005.

RICOEUR, P. Tempo e narrativa. Tradução de Constança Marcondes Cesar e Roberto Leal Ferreira. Campinas: Papirus, 1994.

RICOEUR, P. A memória, a história, o esquecimento. Campinas: Editora da Unicamp, 2007.

SANTOS, M. Prazer, somos o Projetemos! Nice to meet you, we are Projetemos! São Paulo, 2020. 1 vídeo (3 min). Publicado pelo canal Mozart Santos. Disponível em: https://youtu.be/30GdoYsEQwo. Acesso em: 25 abr. 2021.

STIEGLER, B. Technics and time, 1. Palo Alto: Stanford University Press, 1998.

STIEGLER, B. Technics and time, 2. Palo Alto: Stanford University Press, 2009.

submetido em: 30 abr. 2021 | aprovado em: 6 maio 2021 